\title{
Standards of professional practice for genetic metabolic dietitians
}

\author{
Rani H. Singh, PhD, RD, and Melissa M. Kaczmarczyk, MPH
}

\begin{abstract}
New discoveries in the field of genetics and recent developments in newborn screening have created opportunities and challenges for genetic metabolic dietitians, placing increasing demands on dietitians to plan appropriate nutritional interventions for patients with metabolic disorders. An appropriate assessment tool must be developed to identify gaps in training and knowledge to assure that dietitians are prepared for advances in this emerging field. Using a multistage process, the Genetic Metabolic Dietitians International founders group developed a set of professional standards modeled after the American Dietetics Association's Standards of Professional Practice and the National Coalition for Health Professions Education in Genetics's core competencies. The Standards of Professional Practice for Genetic Metabolic Dietitians were validated by means of an electronic questionnaire distributed nationally to dietitians through the PRO-METLAB listserv. Statistical measures were used to determine whether perceived importance was significantly associated with compliance for each of the indicators included in the Standards of Professional Practice. The Standards of Professional Practice for Genetic Metabolic Dietitians will be used to structure continuing education opportunities, guide research and evaluation, and will serve as a basis for certification and professional accreditation. Genet Med 2008:10(4):290-293.
\end{abstract}

Key Words: competencies, genetic metabolic dietetics, standards of professional practice

Completion of the Human Genome Project and technological advances in the field of genetics have led to vast improvements in gene mapping and sequencing. As a result, genetic tools are being used with growing frequency across the health care field. ${ }^{1,2}$ Historically, metabolic dietetics was limited to the treatment of a few single-gene defects, such as phenylketonuria and maple syrup urine disease, ${ }^{3,4}$ but the number of new metabolic conditions being identified and diagnosed is rising rapidly. As disorders are added to the newborn screening panel, demands for nutritional interventions and treatments tailored to the individual and the disorder will only grow. What remains unclear is whether the field of metabolic dietetics is prepared for the opportunities and challenges that genetic advances bring.

To date, evaluating the practice of genetic metabolic dietetics has proved impracticable because of a lack of appropriate instruments, such as assessment tools and professional guidelines. To assess existing gaps in the knowledge and training of metabolic dietitians, a set of standards or competencies would need to be developed. Competencies help to define emerging fields and reduce variations in quality of care. ${ }^{5}$ The American Dietetics Association $(\mathrm{ADA})$ published the Standards of Professional Practice

From the Emory Genetics Metabolic Nutrition Program, Emory University, Decatur, Georgia. Rani H. Singh, PhD, RD, Department Of Human Genetics, Emory University, 2165 North Decatur Road, Decatur, GA 30033.E-mail: rsingh@genetics.emory.edu.

Disclosure: The authors declare no conflicts of interest.

Submitted for publication November 30, 2007.

Accepted for publication January 14, 2008.

DOI: 10.1097/GIM.0b013e31816b443b for dietitians and dietetic technicians in 2005 as a means of describing "a competent level of dietetics practice and professional performance." 6,7 In addition, several specialized areas within the dietetics profession have adapted these standards to fit their specific needs. ${ }^{8-11}$ Nevertheless, the field of genetic metabolic dietetics remains without such a set of competencies. These competencies would serve as a means of evaluating the responsibilities, priorities, and educational needs of practicing genetic metabolic dietitians and establish a foundation for the field. It was to these ends that Genetic Metabolic Dietitians International (GMDI) undertook the current project.

\section{METHODS}

The urgent need for continuing education for metabolic dietitians first became apparent at the fall 2004 national meeting of the GMDI founders. The GMDI founders group consisted of 15 practicing genetic metabolic dietitians from across the United States who had demonstrated leadership in the field of metabolic dietetics based on their involvement in regional and national conferences, active participation in the PNO-METLAB listserv (a listserv specific for the field of genetic metabolic dietetics developed and maintained by the author) and by maintaining visibility in the field. The members of the founders group completed a multistage process to define the unique areas of competency and the levels of competency that are essential to the emerging field of genetic metabolic dietetics. This process involved meetings, conference calls, and communication via e-mail. The founders group met to begin the development of the Standards of Professional Practice for Genetic Metabolic Dietitians on April 9, 2005, after the Ross National 
Metabolic Conference. The meeting began with a brief introduction to competency structure and development and a review of published competencies and articles regarding the appropriate tools for competency development. ${ }^{12-14}$ The group established the target audience, scope, and domains, the latter of which were modeled after those in the ADA's Standards for Professional Practice. ${ }^{7}$ Each member of the founders group submitted a log of their daily activities to delineate the duties of genetic metabolic dietitians. Competencies pertaining to the specific responsibilities of genetic metabolic dietitians, modeled after the National Coalition for Health Professions Education in Genetics's core competencies $^{12}$ and the ADA's Standards for Professional Practice, ${ }^{7}$ were later added under each domain. Special consideration was given to the effect these competencies would have on academia and the education of genetic metabolic dietitians, as well as how to use the competencies to create training guidelines for existing professionals, with an eye toward basing certification and credentialing efforts on the document.

The draft of the Standards of Professional Practice for Genetic Metabolic Dietitians was validated by means of an electronic survey distributed to the PNO-METLAB listserv in November 2006. Of the 227 listserv members who had access to the electronic questionnaire, 65 surveys were submitted with a response rate of $28.6 \%$. Respondents practicing outside of the United States and Canada and respondents who completed only the demographic section of the questionnaire were excluded, leaving 50 completed surveys for analysis. For each indicator, survey respondents were asked (1) whether they perceived the indicator as essential to the practice of genetic metabolic dietetics and (2) whether they regularly applied the indicator to the practice of genetic metabolic dietetics. Descriptive statistics were used when responses to Question 1 were $100 \%$; otherwise, Fisher's exact test was used to determine whether compliance was significantly associated with perceived importance. A response frequency of $<80 \%$ for Question 2 was considered to represent low compliance for that indicator. SAS version 9.0 (SAS Institute, Cary, NC) was used for all analysis. The final version of the Standards of Professional Practice for Genetic Metabolic Dietitians is presented in Figure 1, A and B. ${ }^{7}$ This study was approved by the ethics committee at Emory University.

\section{RESULTS/DISCUSSION}

Of those responding to the survey, $100 \%$ of respondents were registered dietitians and $84 \%$ of respondents worked with a mixed pediatric/adult patient population. The number of metabolic patients seen by responding dietitians ranged from $<10(4 \%)$ to $>200(26 \%)$. Survey participants found most standards and their indicators important; at least $75 \%$ of respondents reported each indicator as essential to the practice of genetic metabolic dietetics. Dietitians applied most indicators to their practice of genetic metabolic dietetics on a regular basis; reported compliance for 42 of the 53 indicators was $80 \%$ or greater. Low compliance was concentrated in four areas: policy, research, budget, and participation in continuing education. Low compliance is indicative of gaps in knowledge and training.

\section{Policy}

Policy and advocacy comprise important components of genetic metabolic dietetics that many dietitians may not pursue or engage in as part of their work. Reported compliance for indicators 1.7 and 5.10, both relating to issues concerning policy and advocacy for client-focused issues, were low: $63 \%(P=0.0013)$ and 58\% $(P<0.0001)$, respectively. Dietitians believed that participating in policy and advocacy were "beneficial," but not essential and admitted that this area often was "placed on the back burner." Dietitians may not perceive policy issues as important because of a lack of knowledge or exposure in this area. Through seminars, continuing education, and involvement with advocacy groups, dietitians can become aware of current policies and develop an understanding of why involvement in policy and advocacy is an important element of the profession.

\section{Research}

Research leads to a more complete understanding of metabolic disorders and drives the field of genetic metabolic dietetics forward, opening up new avenues for treatment and management of metabolic disorders. Reported compliance for 4 of the 10 indicators for Standard 2, the Application of Research (33-51\%), and for indicator 6.5, "participates in quality assurance and research endeavors" (64\%), were low. Compliance was significantly associated with perceived importance for only one indicator, indicator 2.5: "collects measurable data outcomes" $(P=0.0226)$. This implies that dietitians understand the importance of the role of research to the profession, but may not have the opportunity to participate in research studies. Dietitians expressed a desire to conduct research, but noted barriers such as part-time employment status, lack of appropriate patient populations, small practice size, and limited funding. These barriers can be minimized by creating opportunities for research through collaborations between dietitians, health researchers, dietetic practices, and other metabolic centers. Collaborations can be formed by attendance at professional conferences, participation on the PNO-METLAB listserv, and through the formation of a subgroup of the PNOMETLAB listserv specifically designated for genetic metabolic research endeavors. Conducting research is necessary to expand the knowledge of dietitians, dietetic practices, and the field of genetic metabolic dietetics.

\section{Budget}

The utilization and management of resources is an important component of the ADA's Standards of Professional Practice $^{7}$. The GMDI founders group agreed that this component was a basic element of the practice of genetic metabolic dietetics and that it was necessary for genetic metabolic dietitians to have some level of budget involvement. Compliance was low for three indicators related to budget: indicators $4.3(P=$ $0.0014), 4.4(P<0.0001)$, and $5.9(P<0.0001)$. In addition to a significant association between perceived importance and compliance for these three indicators, there was also an increase in the number of missing values per indicator for Stan- 


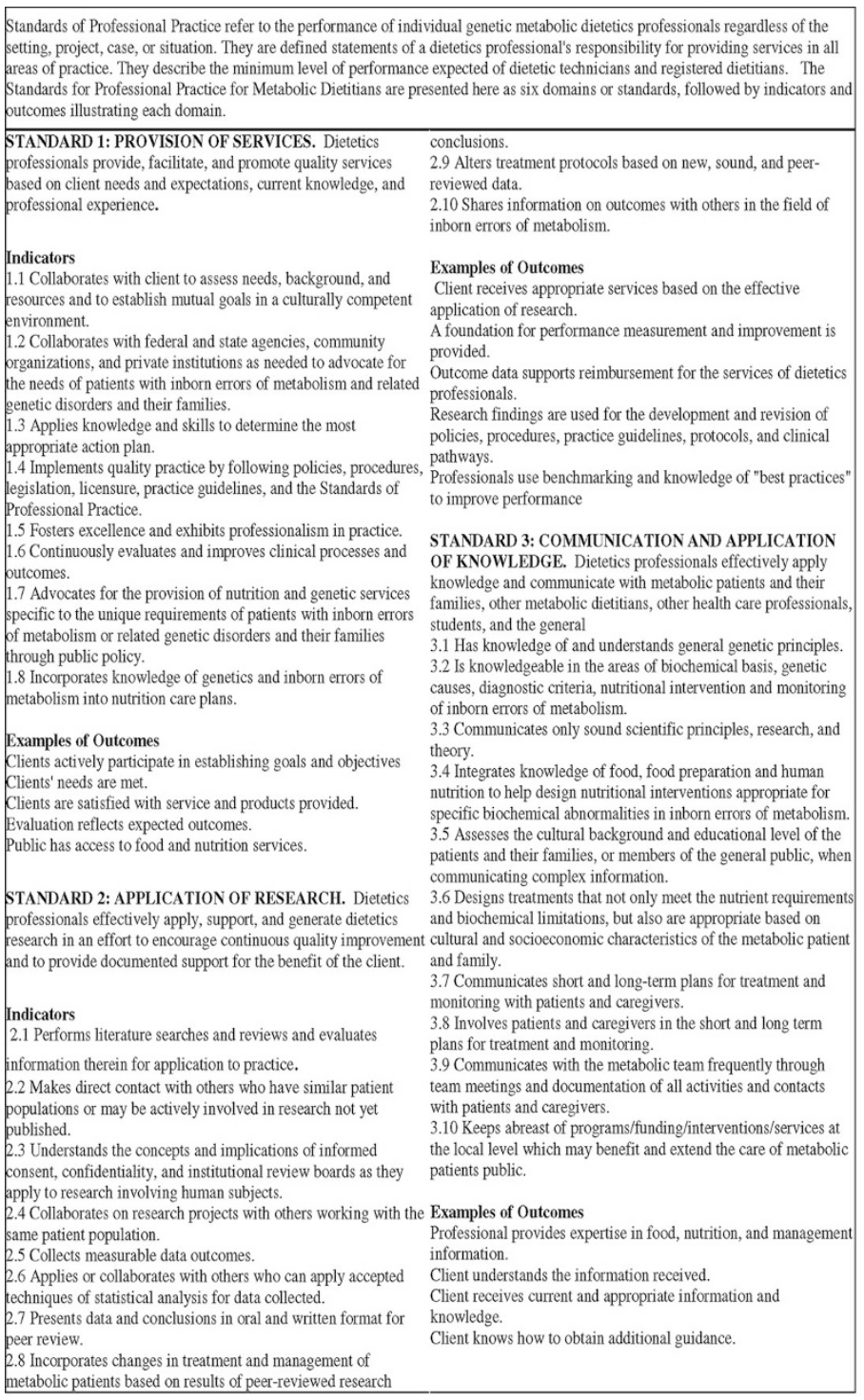

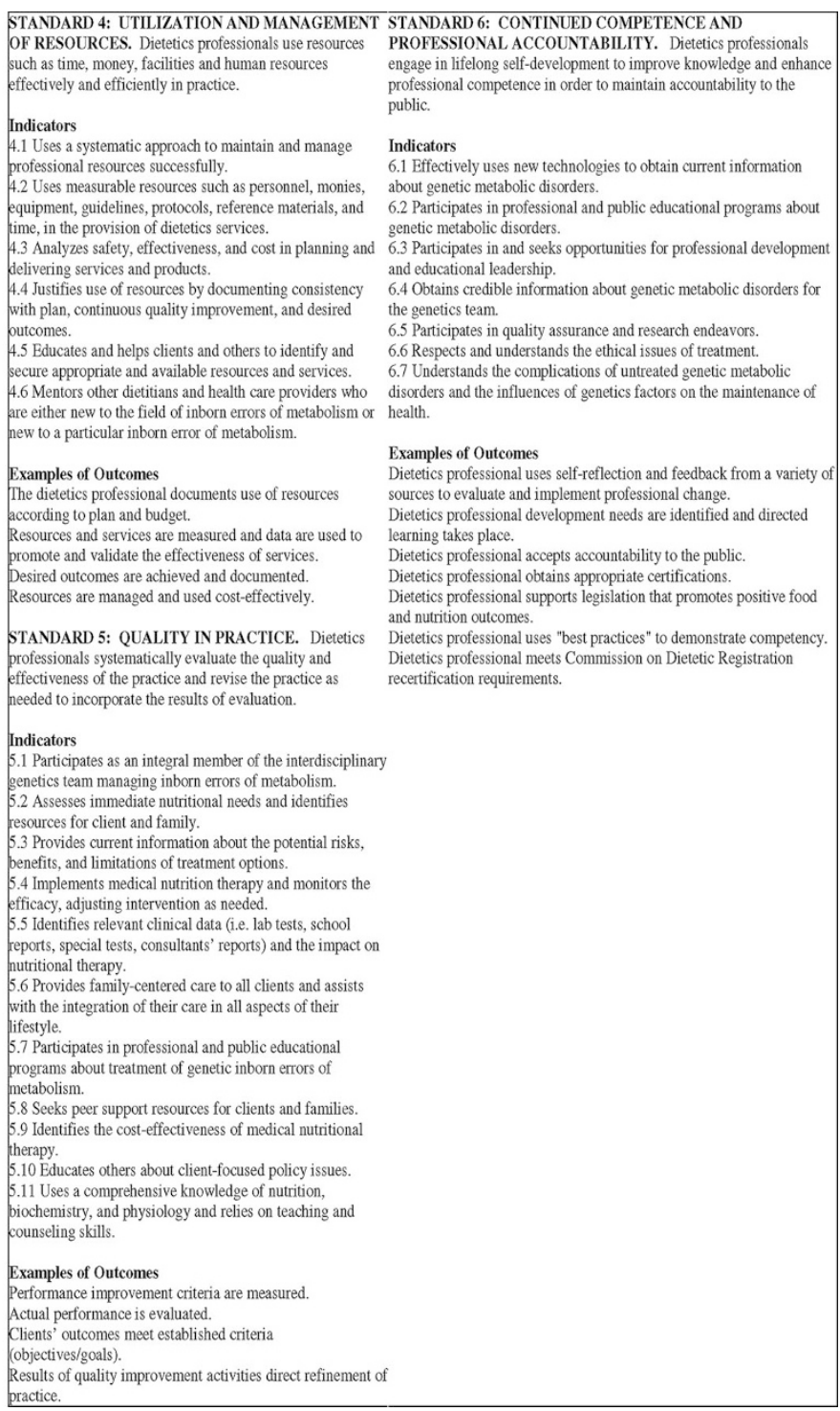

Fig. 1. Standards of professional practice for genetic metabolic dietitians. Based on reference 7.

dard 4: Utilization and Management of Resources compared with the other standards. This suggests that dietitians may have not believed that budget-related items were important to the practice of genetic metabolic dietetics or that these indicators were not applicable to them. Dietitians may not always be involved in budget planning and management. The founders decided to retain the budget-related indicators despite lack of current participation, in anticipation that future credentialing will be based on the Standards of Professional Practice for Genetic Metabolic Dietitians, including the indicators related to budget and resource management. More thought and consideration may need to be given to this area in the future.

\section{Participation in Professional Programs}

Closing existing gaps in training and knowledge and ensuring dietitians have current information regarding genetic metabolic disorders and the treatment of these disorders is dependent on continuing education classes and professional programs. Compli- ance to indicator 5.7, "participates in professional and public educational programs about treatment of genetic inborn errors of metabolism," was $<80 \%$, but was not significantly associated with perceived importance. This indicates that dietitians are aware of the importance of attending continuing education programs about genetic inborn errors of metabolism, but may not attend because of the scarcity of available programs and funding constraints. Currently only one course for genetic metabolic dietitians has been offered. ${ }^{15}$ There is both a demand for and a need to develop continuing education classes focused on genetic metabolic disorders. The organization and implementation of additional continuing education classes is essential for practicing dietitians to keep abreast with current knowledge.

\section{Competencies in Practice}

The Standards of Professional Practice were designed as a means to unify and standardize the profession of genetic met- 
abolic dietetics. The Standards of Professional Practice will be used to structure continuing education opportunities, such as classes, seminars, Web-based applications, workshops, and conferences, as well as to guide research and evaluation. The competencies will also serve as a guide in certification, professional accreditation, and strengthening academic curriculum.

Although still a working draft, the formulation and organization of the Standards of Professional Practice for Genetic Metabolic Dietitians has already supported practical activities toward evaluating and improving upon professional goals and skills. In August 2005, a working draft served as a model in the development of an assessment instrument. The resulting questionnaire was distributed nationally via the PNO-METLAB listserv to identify the level of expertise among metabolic nutritionists in the region and to assist in setting education priorities and educational methodology preferences. Using the standards as a guideline, the questionnaire was able to capture core concepts related to the continuing education needs of metabolic dietitians.

\section{CONCLUSION}

In many areas of health care, including the field of genetic metabolic dietetics, advances in technology may be outpacing education. ${ }^{16,17}$ It became apparent through professional meetings and conferences that an evidence-based approach was needed to identify the gap between education and current practice and to assess the responsibilities of genetic metabolic dietitians. The Standards of Professional Practice for Genetic Metabolic Dietitians serves as a method of evaluation and helps to define the field of genetic metabolic dietetics, as well as what it means to be a genetic metabolic dietitian.

\section{ACKNOWLEDGMENTS}

This project was funded by HRSA Grant U22MC03960.

GMDI Founders Group: Laurie Bernstein, MS, RD, FADA, The Children's Hospital, Denver, CO; Kathryn Camp, MS, RD, CSP, Walter Reed Army Medical Center, Washington, DC; Amy C. Cunningham, MS, LDN, RD, Tulane University Health Sciences Center, New Orleans, LA; Sharon L. Ernst, MPH, RD, CD, University of Utah, Salt Lake City, UT; Dianne M. Frazier, PhD, MPH, RD, University of North Carolina at Chapel Hill, Chapel Hill, NC; Barbara S. Goss, MS, RD, LDN, University of Illinois at Chicago, Chicago, IL; Carol Hartnett, MSc, RD, British Columbia Children's Hospital, Vancouver, BC, Canada; Kathleen Huntington, MS, RD, LD, Oregon Health \& Science University, Portland, OR; Elaina Jurecki, MS, RD, Kaiser Permanente Medical Center, Northern California,
Oakland, CA; Barbara J. Marriage, PhD, RD, Ross Products Division, Abbott Laboratories, Columbus, OH; Helen McCune, MS, RD, University of Florida, Gainesville, FL; Shideh Mofidi, MS, RD, CSP, Mount Sinai School of Medicine, New York, NY; Fran Rohr, MS, RD, Children's Hospital, Boston, MA; Rani H. Singh, $\mathrm{PhD}, \mathrm{RD}$, Emory University, Atlanta, GA; Cristine M. Trahms, MS, RD, CD, FADA, University of Washington, Seattle, WA; Linda Tonyes, MS, RD, St. Christopher's Hospital for Children, Philadelphia, PA; Sandy van Calcar, MS, RD, Waisman Center, University of Wisconsin, Madison, WI; Steven Yannicelli, PhD, RD, SHS North America, Valencia, CA.

\section{References}

1. Goldberg A. Genetics education for the physical therapy profession. JPhys Ther Educ 2005;19:9-15.

2. Kauwell GP. A genomic approach to dietetic practice: are you ready? Top Clin Nutr 2003;18:81-91.

3. Gilbride JA, Katheryn C. Preparation and needs for genetics education in dietetics. Top Clin Nutr 2004;19:316-323.

4. Kozma C. The interface between genomics and nutrition. Top Clin Nutr 2003;18: 73-80.

5. Lacey K, Pritchett E. Nutrition care process and model: ADA adopts road map to quality care and outcomes management [see comment] [erratum appears in $\mathrm{J} \mathrm{Am}$ Diet Assoc 2003;103:1293]. J Am Dietetic Assoc 2003;103:1061-1072.

6. Kieselhorst KJ, Skates J, Pritchett E. American Dietetic Association: standards of practice in nutrition care and updated standards of professional performance. JAm Dietetic Assoc 2005; 105:641-645.

7. Appendix: standards of practice in nutrition care for the registered dietitian, standards of practice in nutrition care for the dietetic technician, registered, and standards of professional performance for dietetics professionals. J Am Diet Assoc 2005; 105:645e.1-645e.10.

8. Emerson M, Kerr P, Soler MDC, Girard T, et al. American Dietetic Association: standards of practice and standards of professional performance for registered dietitians (generalist, specialty, and advanced) in behavioral health care. J Am Diet Assoc 2006;106:608-613.

9. Robien K, Levin R, Pritchett E, Otto M. American Dietetic Association: standards of practice and standards of professional performance for registered dietitians (generalist, specialty, and advanced) in oncology nutrition care. J Am Diet Assoc 2006;106: 946-951.

10. Shoaf LR, Bishirjian KO. Standards of practice for gerontological nutritionists: a mandate for action. The American Dietetic Association. J Am Diet Assoc 1995;95: 1433-1438.

11. Shoaf LR, Bishirjian KO, Schlenker ED. The gerontological nutritionists standards of professional practice for dietetics professionals working with older adults. American Dietetic Association. J Am Diet Assoc 1999;99:863-867.

12. Core Competency Working Group of the National Coalition for Health Professional Education in Genetics. Recommendations of core competencies in genetics essential for all health professionals. Genet Med 2001;3:155-159.

13. Acosta PB, Ryan AS. Functions of dietitians providing nutrition support to patients with inherited metabolic disorders. J Am Diet Assoc 1997;97:783-786; quiz 7-8.

14. The American Dietetic Association Standards of Professional Practice for dietetics professionals [erratum appears in J Am Diet Assoc 1998;98:264]. J Am Diet Assoc 1998;98:83-87.

15. Singh RH. Genetic metabolic nutrition and expanded newborn screening: clinical correlations: A practical training course for metabolic dietitians. Presented at: Emory Conference. Atlanta, Georgia, 2007.

16. Chambers DW, Gilmore CJ, Maillet JO, Mitchell BE. Another look at competencybased education in dietetics. J Am Diet Assoc 1996;96:614-617.

17. Hoge MA. The training gap: an acute crisis in behavioral health education. Adm Policy Ment Health 2002;29:305-317. 